Note: This report has been superseded by PNNL-21218 Rev.1

at: http://www.pnnl.gov/main/publications/external/technical_reports/PNNL-21218Rev1.pdf

\title{
Siting the International Linear Collider at Hanford
}
RT Kouzes
J Fast
DM Asner
HS Miley
RL Brodzinski

March 2012

\section{Pacific Northwest}

NATIONAL LABORATORY

Proudly Operated by Battelle Since 1965 